\section{Commentary: Aberrant vertebral arteries in aortic repair: Small but mighty!}

\author{
Marina Ibrahim, MD, MSc, FRCSC, \\ Jennifer C.-Y. Chung, MD, MSc, FRCSC, \\ Thomas F. Lindsay, MD, MSc, FRCSC, ${ }^{\text {b }}$ and \\ Maral Ouzounian, MD, PhD, FRCSC ${ }^{\mathrm{a}}$
}

\begin{abstract}
Aberrant origin of the vertebral artery (VA) is an uncommon anatomic variant. The VA originates as the first branch of the ipsilateral subclavian artery. Its aberrant origin is variable and can arise from the aortic arch, common, or internal or external carotid arteries. ${ }^{1,2}$ Despite being clinically asymptomatic, knowledge of the precise origin of aberrant VA can be critical before performing open surgical or endovascular procedures involving the arch or distal aorta.

Martin-Gonzalez and colleagues ${ }^{3}$ present a case of a patient with an extent I thoracoabdominal aortic aneurysm with aberrant right and left VAs originating distal to the left subclavian artery (LSA). They describe their open thoracoabdominal aortic aneurysm repair technique with preservation of both VAs through direct reimplantation. This report demonstrates that when the origin of 1 or more aberrant VAs is located in the intended area of replacement, critical steps must be taken to preserve perfusion in certain clinical situations.
\end{abstract}

\section{INCIDENCE}

Multiple aberrant origins of both VAs have been reported. ${ }^{4}$ The most common aberrancy is the left VA origin off the aortic arch between the left common carotid artery and LSA, with a prevalence of $2.4 \%-5.8 \% .^{1,5-7}$ In contrast, an aortic origin of the right VA is rare. ${ }^{2}$ Although the true incidence remains unknown, ${ }^{8}$ only 13 cases of an

\footnotetext{
From the Divisions of ${ }^{\mathrm{a}}$ Cardiovascular Surgery, and ${ }^{\mathrm{b}}$ Vascular Surgery, Peter Munk Cardiac Centre, Toronto General Hospital, University of Toronto, Toronto, Ontario, Canada.

Disclosures: The authors reported no conflicts of interest.

The Journal policy requires editors and reviewers to disclose conflicts of interest and to decline handling or reviewing manuscripts for which they may have a conflict of interest. The editors and reviewers of this article have no conflicts of interest.

Received for publication March 28, 2021; revisions received March 28, 2021; accepted for publication March 31, 2021; available ahead of print April 3, 2021.

Address for reprints: Maral Ouzounian, MD, PhD, FRCSC, Division of Cardiac Surgery, Toronto General Hospital, 200 Elizabeth St, 4N-464, Toronto, M5G2C4, Ontario, Canada (E-mail: Maral.ouzounian@uhn.ca).

JTCVS Techniques 2021;7:57-8

2666-2507

Copyright (c) 2021 The Author(s). Published by Elsevier Inc. on behalf of The American Association for Thoracic Surgery. This is an open access article under the CC BY-NC-ND license (http://creativecommons.org/licenses/by-nc-nd/4.0/).

https://doi.org/10.1016/j.xjtc.2021.03.032
}

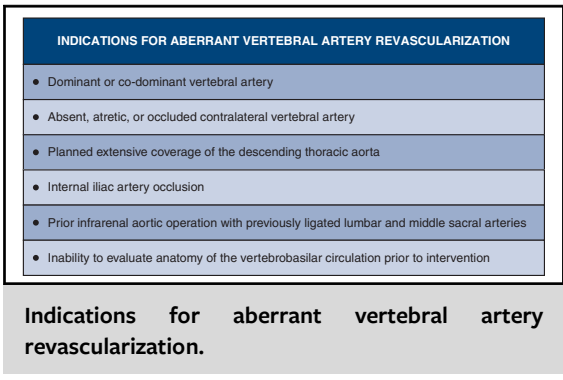

CENTRAL MESSAGE

When the aberrant vertebral artery origin is located in the intended area of replacement or zone of endovascular coverage, critical steps must be taken to preserve its perfusion in certain situations.

aberrant right VA with an origin distal to the LSA have been reported. ${ }^{4}$

\section{INDICATIONS FOR VA REVASCULARIZATION}

VA variants are usually of no clinical significance except when treating cerebrovascular or thoracic aortic pathology. ${ }^{9,10}$ Posterior circulation strokes or vertebrobasilar insufficiency and spinal cord ischemia are well-described complications of LSA coverage during thoracic endovascular aortic repair in patients with normal VA origins. ${ }^{11}$ Hence, indications to preserve perfusion of the aberrant VA can be extrapolated from published indications to preserve perfusion to the LSA. ${ }^{12}$ These include dominance of the aberrant VA; absent, atretic, or occluded contralateral VA; or inability to evaluate the anatomy of the vertebrobasilar circulation before intervention. ${ }^{13}$ As the VA provides perfusion to the spinal cord, planned extensive coverage of the descending thoracic or thoracoabdominal aorta, previous infrarenal aortic operation with previously ligated lumbar and middle sacral arteries, or internal iliac artery occlusion are also indications for preservation. ${ }^{13,14}$ In addition, in elective settings, where coverage of the aberrant VA is necessary, routine revascularization should be attempted when possible. ${ }^{13}$ The Figure 1 summarizes the indications for VA revascularization.

\section{SURGICAL TECHNIQUES FOR ABERRANT VA REVASCULARIZATION}

Surgical options for VA revascularization are similar to the techniques used for symptomatic VA occlusive disease. 




FIGURE 1. Indications for aberrant vertebral artery revascularization.

The proximal VA can be revascularized by reattaching it on a patch to the aortic repair, transposing it to the common carotid artery, or by performing a vein graft bypass. ${ }^{15,16}$ Proximal VA reconstructions can be performed safely with low stroke and mortality rates of $0.9 \% .{ }^{15-17}$

In summary, although aberrant VA origins are usually asymptomatic, it is important to identify them before aortic arch or distal aortic intervention. VA artery revascularization is indicated in certain clinical situations before covering or ligating its origin during aortic repair.

\section{References}

1. Yuan SM. Aberrant origin of vertebral artery and its clinical implications. Braz J Cardiovasc Surg. 2016;31:52-9.

2. Albayram S, Gailloud P, Wasserman BA. Bilateral arch origin of the vertebral arteries. AJNR Am J Neuroradiol. 2002;23:455-8.

3. Martín-González I, Gómez-Planas J, Tebar Botí E. Bilateral aberrant vertebral arteries from descending thoracic aorta in open thoracoabdominal aneurysm repair. J Thorac Cardiovasc Surg Tech. 2021;7:53-6.

4. Case D, Seinfeld J, Folzenlogen Z, Kumpe D. Anomalous right vertebral artery originating from the aortic arch distal to the left subclavian artery: a case report and review of the literature. J Vasc Interv Neurol. 2015;8:21-4.

5. Al-Okaili R, Schwartz ED. Bilateral aortic origins of the vertebral arteries with right vertebral artery arising distal to left subclavian artery: case report. Surg Neurol. 2007;67:174-6; discussion 6.

6. Komiyama M, Morikawa T, Nakajima H, Nishikawa M, Yasui T. High incidence of arterial dissection associated with left vertebral artery of aortic origin. Neurol Med Chir (Tokyo). 2001;41:8-11; discussion-2.
7. Lemke AJ, Benndorf G, Liebig T, Felix R. Anomalous origin of the right vertebral artery: review of the literature and case report of right vertebral artery origin distal to the left subclavian artery. AJNR Am J Neuroradiol. 1999; 20:1318-21.

8. Canyigit M, Akgoz A, Koksal A, Yucesoy C. Aberrant right vertebral artery: a rare aortic arch anomaly. Br J Radiol. 2009;82:789-91.

9. Atkin GK, Grieve PP, Vattipally VR, Ravikumar KH, Das SK. The surgical management of aortic root vessel anomalies presenting in adults. Ann Vasc Surg. 2007; 21:525-34.

10. Jakanani GC, Adair W. Frequency of variations in aortic arch anatomy depicted on multidetector CT. Clin Radiol. 2010;65:481-7.

11. Patterson BO, Holt PJ, Nienaber C, Fairman RM, Heijmen RH, Thompson MM. Management of the left subclavian artery and neurologic complications after thoracic endovascular aortic repair. J Vasc Surg. 2014;60:1491-7.e1.

12. Peterson BG, Eskandari MK, Gleason TG, Morasch MD. Utility of left subclavian artery revascularization in association with endoluminal repair of acute and chronic thoracic aortic pathology. J Vasc Surg. 2006;43:433-9.

13. Matsumura JS, Rizvi AZ. Left subclavian artery revascularization: Society for Vascular Surgery practice guidelines. J Vasc Surg. 2010;52(4 Suppl): $65 \mathrm{~s}-70 \mathrm{~s}$.

14. Woo EY, Bavaria JE, Pochettino A, Gleason TG, Woo YJ, Velazquez OC, et al. Techniques for preserving vertebral artery perfusion during thoracic aortic stent grafting requiring aortic arch landing. Vasc Endovasc Surg. 2006; 40:367-73.

15. Berguer R, Bauer RB. Vertebral artery reconstruction. a successful technique in selected patients. Ann Surg. 1981;193:441-7.

16. Berguer R. Distal vertebral artery bypass: technique, the "occipital connection," and potential uses. J Vasc Surg. 1985;2:621-6.

17. Blumberg SN, Adelman MA, Maldonado TS. Aberrant left vertebral artery transposition and concomitant carotid-subclavian bypass for treatment of acute intramural hematoma with thoracic endovascular aortic repair. J Vasc Surg. 2017;65: $860-4$. 